\title{
CARACTERIZAÇÃO QUÍMICA DE EXTRATOS HIDROSSOLÚVEIS DESIDRATADOS DE ARROZ E SOJA ${ }^{1}$
}

\author{
SIMONE MIRANDA FERNANDES ${ }^{2}$, SIN-HUEI WANG ${ }^{3}$, LAIR CHAVES CABRAL ${ }^{4}$ \\ e JOÃO TOMAZ DA SILVA BORGES ${ }^{5}$
}

\begin{abstract}
RESUMO - O presente trabalho teve por objetivo caracterizar quimicamente os extratos hidrossolúveis desidratados de arroz (Oryza sativa L.) e de soja (Glycine max (L.) Merrill). Os processos utilizados para a obtenção dos extratos hidrossolúveis foram: maceração do arroz e da soja, desintegração, centrifugação, adição de ácido cítrico, fervura e secagem por atomização. A caracterização química foi realizada através das seguintes determinações: composição centesimal aproximada, composição de minerais e atividade do inibidor de tripsina. Com o aumento das proporções de soja (0 a $50 \%$ ), os extratos hidrossolúveis desidratados tiveram aumento nos teores de proteína, extrato etéreo, cinzas e fibra crua, porém diminuição no teor de carboidratos. Os teores de $\mathrm{P}, \mathrm{K}, \mathrm{Mg}, \mathrm{Cu}$ e Co foram altos em alguns extratos hidrossolúveis desidratados estudados, os quais foram semelhantes à indicação diária na "Recommended Dietary Allowances", enquanto os demais minerais se mostraram em pequenas quantidades ou apenas traços. Não foi detectada atividade do inibidor de tripsina.
\end{abstract}

Termos para indexação: Glycine max, Oryza sativa, composição centesimal, composição de minerais.

\author{
CHEMICAL CHARACTERIZATION OF DEHYDRATED RICE \\ AND SOYBEAN WATER-SOLUBLE EXTRACTS
}

\begin{abstract}
The objective of the present study was to evaluate the chemical characteristics of dehydrated water-soluble extracts of rice (Oryza sativa L.) and soybean (Glycine max (L.) Merrill). The preparation included soaking of the rice and soybean, desintegration, centrifugation, addition of citric acid, boiling and spray drying. Dehydrated water-soluble extracts were analysed for their proximate composition, minerals content and trypsin inhibitor activity. Results indicated that an increase in the proportion of soybean ( 0 to $50 \%$ ) resulted in an increase in the content of proteins, oil, ash, crude fiber, as well as a decrease in the percentage of carbohydrates. The content of $\mathrm{P}, \mathrm{K}, \mathrm{Mg}, \mathrm{Cu}$ and $\mathrm{Co}$ in some of the extracts were particularly high and were comparable with those of the Recommended Dietary Allowances. Other minerals were detected in low or trace amounts. No trypsin inhibitor activity was detected.
\end{abstract}

Index terms: Glycine max, Oryza sativa, proximate composition, mineral composition.

\footnotetext{
${ }^{1}$ Aceito para publicação em 4 de junho de 1999.

${ }^{2}$ Econ. Doméstica, M.Sc.

${ }^{3}$ Bioq., Dra., Profa. Adjunto, Dep. de Economia Doméstica, ICHS, UFRRJ, CEP 23851-970 Seropédica, RJ.

${ }^{4}$ Quím., Dr., Embrapa-Centro Nacional de Pesquisa de Tecnologia Agroindustrial de Alimentos (CTAA), Av. das Américas, no 29501, CEP 23020-470 Guaratiba, RJ. E-mail:1cc@ctaa.embrapa.br

${ }^{5}$ Econ. Doméstica,
}

\section{INTRODUÇÃO}

A desnutrição protéica, causada pela deficiência de disponibilidade e alto custo dos alimentos, é um dos mais sérios problemas de desnutrição em crianças no mundo. Por esse motivo, esforços têm sido empreendidos para a introdução de novos alimentos infantis de baixo custo e alto valor calórico-protéico (Segura et al., 1988). 
Considera-se que o Brasil é um dos maiores produtores mundiais de soja e de arroz e, de acordo com Elías et al. (1968) e Steinke \& Hopkins (1983), a mistura de arroz e soja em proporções adequadas mostra um efeito complementar mútuo de aminoácidos. Além da qualidade protéica, a mesma mistura apresenta excelente fonte de minerais, podendo em determinada proporção suprir ou complementar a recomendação diária de nutrientes (National Research Council, 1989) para as crianças, evitando, assim, patologias ocasionadas pela deficiência nutricional (Krause \& Mahan, 1994; Willians, 1997). A elaboração de extratos hidrossolúveis desidratados de arroz e soja se torna interessante para atender a tal necessidade. Os extratos hidrossolúveis desidratados oferecem vantagens de conter não só proteínas de boa qualidade e baixo custo, mas também minerais, além de possuírem uma longa vida de prateleira. Por essas razões, no presente trabalho objetivou-se a caracterização química de extratos hidrossolúveis desidratados de arroz e soja, em diferentes proporções.

\section{MATERIAL E MÉTODOS}

As matérias-primas utilizadas para os estudos foram grãos de arroz e de soja (cultivar BR 16, safra de 1996), ambos adquiridos no comércio e na Embrapa-Serviço de Produção de Sementes Básicas (SPSB), Ponta Grossa, PR, respectivamente.

A obtenção do extrato hidrossolúvel desidratado, as análises químicas e a atividade do inibidor de tripsina foram feitas em triplicata.

Os grãos de arroz e de soja foram, separadamente, macerados em água na proporção 1:4 (grão:água) à temperatura ambiente, durante 30 minutos para o arroz e 16 horas para a soja. Em seguida, a água de maceração da soja foi drenada, porém utilizou-se a do arroz. Os grãos de arroz e soja, após o tratamento anterior, foram misturados nas proporções de 100:0, 90:10, 80:20, 70:30, 60:40 e $50: 50 \%$ (base seca). Posteriormente, foram desintegrados no liqüidificador Waring, durante três minutos, com adição da água de maceração do arroz completada com água potável, obedecendo as proporções de 1:9 ou 1:8 (base seca). Após a desintegração, o conteúdo foi transferido para uma centrífuga de cesto, onde o resíduo foi separado, obtendo-se um extrato com 4-7\% de sólidos. O extrato foi

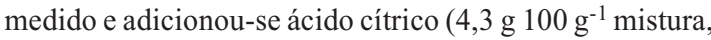
$\mathrm{pH}$ entre 3,3 e 3,5), sendo submetido à fervura por
15 minutos. Logo após, o controle e as cinco fórmulas de extrato foram secas por atomização com temperatura de entrada e de saída de $200^{\circ} \mathrm{C} \mathrm{e} 90^{\circ} \mathrm{C}$, respectivamente, tendo como produtos finais, extratos hidrossolúveis desidratados.

Foram realizadas as seguintes análises da composição centesimal dos extratos hidrossolúveis desidratados: umidade, extrato etéreo, proteína bruta e cinzas determinados conforme American Association of Cereal Chemists (1969), e fibra crua, de acordo com Kamer \& Ginkel (1952).

Também foram determinados: $\mathrm{P}, \mathrm{Ca}, \mathrm{K}, \mathrm{Na}, \mathrm{Mg}, \mathrm{Fe}$, $\mathrm{Cu}, \mathrm{Co}, \mathrm{Zn}, \mathrm{Cr}, \mathrm{Se}, \mathrm{Mn}$, Mo e Al, de acordo com os métodos da Association of Official Analytical Chemists (1997). A quantificação foi realizada em espectrofotômetro de emissão de plasma ICP Spectroflama. O teor de minerais presente na amostra foi determinado por espectrometria de emissão atômica, após digestão completa da amostra com ácido nítrico e ácido perclórico.

A atividade do inibidor de tripsina dos extratos hidrossolúveis desidratados foi determinada, segundo o método original de Kunitz, conforme descrito por Kakade et al. (1969), consistindo na digestão da caseína pela enzima tripsina, onde determinou-se sua atividade pela introdução do inibidor dos produtos desidratados previamente submetidos ou não à fervura. Considerando-se a definição de unidade de tripsina (UT) como sendo o aumento de 0,01 unidade de absorbância a $280 \mathrm{~nm}$ nas condições do teste, calcularam-se as unidades de tripsina inibida (UTI) pela diferença entre as unidades de tripsina totais (UT) da atividade máxima e as da amostra contendo o inibidor.

Foram usados o delineamento inteiramente casualizado (DIC), com três repetições, e as análises de variância e de comparação das médias pelo teste de Tukey a $5 \%$ de probabilidade. Todas as análises foram efetuadas segundo os métodos descritos por Pimentel-Gomes (1982).

\section{RESULTADOS E DISCUSSÃO}

Usando-se os grãos de arroz e soja em diferentes proporções, foram obtidos extratos hidrossolúveis desidratados, cujas composições químicas parciais estão ilustradas nas Tabelas 1 e 2.

A Tabela 1 apresenta em base seca a composição centesimal aproximada dos extratos hidrossolúveis desidratados de arroz e soja em diferentes proporções. Observa-se que à medida que é incrementada a proporção de soja (0 a 50\%), há um aumento significativo no percentual de proteína ( $7,23 \%$ a $35,81 \%)$, 
extrato etéreo $(0,62 \%$ a $5,86 \%)$, cinzas $(1,37 \%$ a $4,55 \%)$ e fibra crua $(1,03 \%$ a $1,95 \%)$. Porém o percentual de carboidratos $(89,75 \%$ a $51,83 \%)$ diminui com o aumento das proporções de soja. Esses resultados são semelhantes aos encontrados por Cruz et al. (1983).

A Tabela 2 mostra a composição em minerais (mg $100 \mathrm{~g}^{-1}$, base seca) dos extratos hidrossolúveis desidratados de arroz e soja em diferentes proporções. Os minerais encontrados em maiores teores foram: $\mathrm{P}, \mathrm{Ca}, \mathrm{K}, \mathrm{Na}$ e $\mathrm{Mg}$, enquanto os demais minerais foram detectados em pequenas quantidades ou apenas traços.

Verifica-se pela Tabela 2 que os teores de P e Ca aumentam linearmente com o aumento das proporções de soja (0 a 50\%). Resultado semelhante foi observado por Cruz et al. (1983) em uma farinha mista de arroz e soja pré-cozida por extrusão, assim como por Segura et al. (1988), em um formulado infantil à base de arroz, soja e fruta.

Os conteúdos de $\mathrm{P}$ presentes nos extratos hidrossolúveis desidratados são altos, principalmente em relação às fórmulas, contendo, respectivamen-

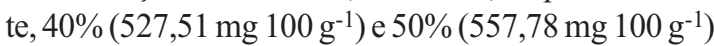
de soja. Ambas as fórmulas podem atender a 100\% do recomendado diário em National Research Council (1989) para os lactentes alimentados com fórmulas, e de $66 \%$ a $70 \%$ para as crianças de 1 a 10 anos e todos os adultos. Por sua vez, os teores de Ca nos extratos hidrossolúveis desidratados não são tão relevantes, em comparação com os de P.

De acordo com Krause \& Mahan (1994) e Willians (1997), o P e o Ca são elementos que se encontram lado a lado em muitos compostos do organismo. Eles possuem inúmeras funções corporais, sendo a principal estrutural. Proporções adequadas desses minerais na dieta evitam patologias tais como raquitismo, osteoporose, osteomalácia, hipercalciúria reabsorsiva, hipofosfatemia, hiperfosfatemia, tetania, entre outras.

$\mathrm{Na}$ Tabela 2 encontram-se os teores de $\mathrm{K}$ e Na. Nota-se que, à medida que aumenta a proporção de soja ( 0 a 50\%) nos extratos hidrossolúveis desidratados, há um aumento significativo no percentual de

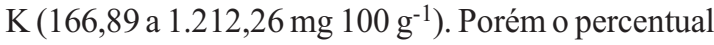
de $\mathrm{Na}\left(47,14\right.$ a $\left.35,71 \mathrm{mg} 100 \mathrm{~g}^{-1}\right)$ diminui com o aumento das proporções de soja (0 a 50\%). De acordo com Estados Unidos (1963), o arroz é uma boa fonte de $\mathrm{Na}$, enquanto a soja se sobressai pelo elevado teor de $\mathrm{K}$, explicando, portanto, os resultados encontrados.

Os extratos hidrossolúveis desidratados com mais de $10 \%$ de soja podem suprir $100 \%$ do K recomendado para dieta diária de lactentes $(500 \mathrm{mg})$, e a fórmula com 50\% (1.212,26 mg $\left.100 \mathrm{~g}^{-1}\right)$ de soja pode atender a todas as necessidades diárias de $\mathrm{K}$ recomendadas

TABELA 1. Composição centesimal aproximada (\% base seca) dos extratos hidrossolúveis desidratados de arroz e soja em diferentes proporções ${ }^{1}$.

\begin{tabular}{|c|c|c|c|c|c|}
\hline $\begin{array}{c}\text { Extrato } \\
\text { hidrossolúvel } \\
\text { desidratado } \\
\text { (arroz:soja) }\end{array}$ & $\begin{array}{l}\text { Proteína } \\
\qquad \%)\end{array}$ & $\begin{array}{c}\text { Extrato etéreo } \\
(\%)\end{array}$ & $\begin{array}{l}\text { Cinzas } \\
(\%)\end{array}$ & $\begin{array}{c}\text { Fibra crua } \\
(\%)\end{array}$ & $\begin{array}{c}\text { Carboidratos }{ }^{2} \\
(\%)\end{array}$ \\
\hline 100:0 & $7,23 \mathrm{f}$ & $0,62 \mathrm{f}$ & $1,37 \mathrm{f}$ & $1,03 \mathrm{e}$ & $89,75 \mathrm{a}$ \\
\hline $90: 10$ & $13,65 \mathrm{e}$ & $1,39 \mathrm{e}$ & $2,16 \mathrm{e}$ & $1,14 \mathrm{de}$ & $81,66 b$ \\
\hline $80: 20$ & $17,77 \mathrm{~d}$ & $2,59 \mathrm{~d}$ & $2,61 \mathrm{~d}$ & $1,31 \mathrm{~d}$ & $75,72 \mathrm{c}$ \\
\hline $70: 30$ & $22,88 \mathrm{c}$ & $3,79 \mathrm{c}$ & $3,06 \mathrm{c}$ & $1,69 \mathrm{c}$ & $68,58 \mathrm{~d}$ \\
\hline $60: 40$ & $33,48 b$ & $4,91 b$ & $4,27 b$ & $1,89 \mathrm{ab}$ & $55,45 \mathrm{e}$ \\
\hline $50: 50$ & $35,81 \mathrm{a}$ & $5,86 \mathrm{a}$ & $4,55 \mathrm{a}$ & $1,95 \mathrm{~b}$ & $51,83 \mathrm{f}$ \\
\hline D.M.S. ${ }^{3}$ & 1,31 & 0,42 & 0,13 & 0,18 & 1,24 \\
\hline C.V. (\%) & 2,20 & 4,79 & 1,53 & 4,38 & 0,64 \\
\hline
\end{tabular}

${ }^{1}$ As médias seguidas de letras diferentes nas colunas diferem estatisticamente entre si pelo teste de Tukey a 5\% de probabilidade.

2 Calculado pela diferença.

3 Diferença mínima significativa. 
TABELA 2. Composição em minerais (mg $100 \mathrm{~g}^{-1}$, base seca) dos extratos hidrossolúveis desidratados de arroz e soja em diferentes proporções ${ }^{1}$.

\begin{tabular}{|c|c|c|c|c|c|c|c|c|}
\hline \multirow[t]{2}{*}{ Mineral } & \multicolumn{6}{|c|}{ Extrato hidrossolúvel desidratado (arroz:soja) } & \multirow[t]{2}{*}{ D.M.S. $^{2}$} & \multirow{2}{*}{$\begin{array}{l}\text { C.V. } \\
(\%)\end{array}$} \\
\hline & 100:0 & $90: 10$ & $80: 20$ & $70: 30$ & $60: 40$ & $50: 50$ & & \\
\hline Fósforo & $168,05 f$ & $292,05 \mathrm{e}$ & $354,47 d$ & $476,98 \mathrm{c}$ & $527,51 b$ & $557,78 \mathrm{a}$ & 2,12 & 0,20 \\
\hline Cálcio & $47,88 \mathrm{f}$ & $49,54 \mathrm{e}$ & $61,76 \mathrm{~d}$ & $81,99 c$ & $86,24 b$ & $92,78 \mathrm{a}$ & 0,99 & 0,52 \\
\hline Potássio & $166,89 f$ & $444,50 \mathrm{e}$ & $681,74 d$ & $957,08 \mathrm{c}$ & $988,55 b$ & $1212,26 a$ & 2,79 & 0,14 \\
\hline Sódio & $47,14 \mathrm{a}$ & $41,74 b$ & $40,54 \mathrm{c}$ & $39,46 \mathrm{~d}$ & $38,52 \mathrm{~d}$ & $35,71 \mathrm{e}$ & 0,94 & 0,85 \\
\hline Magnésio & $70,36 f$ & $113,48 \mathrm{e}$ & $145,59 \mathrm{~d}$ & $187,00 \mathrm{c}$ & $206,87 b$ & $213,64 \mathrm{a}$ & 2,14 & 0,50 \\
\hline Ferro & $2,17 \mathrm{~d}$ & $2,43 c$ & $2,47 \mathrm{c}$ & $3,25 b$ & $3,26 b$ & $3,76 a$ & 0,16 & 2,02 \\
\hline Cobre & $0,58 \mathrm{~d}$ & $0,60 \mathrm{~d}$ & $0,81 \mathrm{c}$ & $1,20 \mathrm{~b}$ & $1,21 \mathrm{~b}$ & $1,45 \mathrm{a}$ & 0,05 & 1,77 \\
\hline Cobalto & $0,48 \mathrm{a}$ & $0,47 \mathrm{a}$ & $0,46 a b$ & $0,46 a b$ & $0,45 \mathrm{ab}$ & $0,43 b$ & 0,03 & 2,17 \\
\hline Zinco & $3,32 f$ & $3,63 \mathrm{e}$ & $3,76 \mathrm{~d}$ & $4,13 c$ & $4,26 \mathrm{~b}$ & $4,49 a$ & 0,08 & 0,76 \\
\hline Cromo & $0,17 \mathrm{a}$ & $0,15 \mathrm{ab}$ & $0,15 \mathrm{ab}$ & $0,13 b c$ & $0,11 \mathrm{~cd}$ & $0,11 \mathrm{~cd}$ & 0,03 & 7,14 \\
\hline Selênio & 4,06 & 4,07 & 4,10 & 4,11 & 4,16 & 4,22 & - & 9,02 \\
\hline Manganês & 0,094 & 0,094 & 0,095 & 0,096 & 0,096 & 0,096 & - & 1,69 \\
\hline Molibdênio & 0,33 & 0,40 & 0,44 & 0,44 & 0,50 & 0,61 & - & 0,01 \\
\hline Alumínio & $8,14 \mathrm{a}$ & $7,35 b$ & $7,11 \mathrm{c}$ & $6,24 d$ & $6,13 \mathrm{~d}$ & $5,21 \mathrm{e}$ & 0,62 & 0,11 \\
\hline
\end{tabular}

1 As médias seguidas de letras diferentes nas linhas diferem estatisticamente entre si pelo teste de Tukey a $5 \%$ de probabilidade.

2 Diferença mínima significativa.

tanto para lactentes como para crianças de 1 a 10 anos (1.000 mg) (National Research Council, 1989).

Willians (1997) constatou que o K regula, junto com o $\mathrm{Na}$ e o $\mathrm{Ca}$, a estimulação neuromuscular, a transmissão de impulsos eletroquímicos e a concentração das fibras musculares, e a deficiência de K e $\mathrm{Na}$ ocasiona perdas em doenças gastrointestinais, diarréia, desequilíbrio hídrico e ácido-básico, entre outras.

A Tabela 2 ilustra os teores de Mg dos extratos hidrossolúveis desidratados. Verifica-se que com o aumento das proporções de soja (0 a 50\%), ocorre um aumento linear nos conteúdos de $\mathrm{Mg}$ (70,36 a $\left.213,64 \mathrm{mg} 100 \mathrm{~g}^{-1}\right)$. Apenas $10 \%$ de soja no extrato hidrossolúvel desidratado já pode atender $100 \%$ do recomendado diário em National Research Council (1989) para lactentes (40 mg) e crianças de 1 a 10 anos (80 mg).

$\mathrm{Na}$ Tabela 2 são encontrados os teores de $\mathrm{Fe}, \mathrm{Cu}$ e Co. Observa-se que com o aumento das proporções de soja ( 0 a 50\%) nos extratos hidrossolúveis desidratados, há um aumento linear nos teores de $\mathrm{Fe}\left(2,17\right.$ a 3,76 mg $\left.100 \mathrm{~g}^{-1}\right)$ e Cu$\left(0,58\right.$ a 1,45 mg $\left.100 \mathrm{~g}^{-1}\right)$ e uma ligeira diminuição nos teores de Co $(0,48$ a $\left.0,43 \mathrm{mg} 100 \mathrm{~g}^{-1}\right)$. O resultado obtido em relação ao $\mathrm{Fe}$ é compatível ao encontrado por Segura et al. (1988) em um formulado infantil à base de arroz, soja e fruta.

Krause \& Mahan (1994) e Willians (1997) reportaram que o Fe desempenha um papel importante na síntese da hemoglobina, no transporte de oxigênio e na oxidação celular, ao passo que o $\mathrm{Cu}$, associado ao $\mathrm{Fe}$, atuam nos sistemas de enzimas, síntese da hemoglobina. Já o Co é o constituinte da vitamina $\mathrm{B}_{12}$, mantendo as células vermelhas do sangue. Os níveis diários recomendados em National Research Council (1989) para os lactentes estão em torno de $8 \mathrm{mg}$ com referência ao $\mathrm{Fe}$; $0,5 \mathrm{mg}$ quanto ao $\mathrm{Cu}$, e traços em relação ao Co, e para as crianças de 1 a 10 anos, $10 \mathrm{mg}$ de $\mathrm{Fe}, 0,8 \mathrm{mg}$ de $\mathrm{Cu}$, e traços de cobalto. Desta forma, sugere-se que os extratos hidrossolúveis desidratados com mais de $10 \%$ de soja já podem suprir todas as necessidades diárias de $\mathrm{Cu}$ e $\mathrm{Co}$ recomendadas tanto para lactentes como para crianças de 1 a 10 anos.

Os outros minerais traços essenciais são $\mathrm{Zn}, \mathrm{Cr}$, Se, Mn, Mo e Al, cujos teores são mostrados na Tabela 2. Os teores de $\mathrm{Zn}\left(3,32\right.$ a 4,49 mg $\left.100 \mathrm{~g}^{-1}\right)$ aumentam e os teores de $\operatorname{Cr}\left(0,17\right.$ a $\left.0,11 \mathrm{mg} 100 \mathrm{~g}^{-1}\right) \mathrm{e}$ $\mathrm{Al}\left(8,14\right.$ a 5,21 mg $\left.100 \mathrm{~g}^{-1}\right)$ diminuem com o aumento das proporções de soja (0 a 50\%). Por outro lado, os 
conteúdos de Se, Mn e Mo não se diferenciam entre as diferentes amostras.

Não houve nenhuma atividade residual do inibidor de tripsina nos extratos hidrossolúveis desidratados estudados, mostrando que a fervura por 15 minutos, utilizada durante os preparos, foi suficiente para inativar completamente o inibidor de tripsina da soja. Resultado semelhante foi verificado por Wang et al. (1997), os quais constataram uma inativação total do inibidor de tripsina na bebida à base de extrato hidrossolúvel de arroz e de soja fervida por 15 minutos, utilizando-se proporção de mistura:água de 1:12.

\section{CONCLUSÕES}

1. Com o aumento das proporções de soja (0 a 50\%) nos extratos hidrossolúveis desidratados de arroz e soja, há aumento nos teores de proteínas, extrato etéreo, cinzas, fibra crua, $\mathrm{P}, \mathrm{Ca}, \mathrm{K}, \mathrm{Mg}, \mathrm{Fe}, \mathrm{Cu}$ e $\mathrm{Zn}$; e diminuição nos teores de carboidratos, $\mathrm{Na}$, $\mathrm{Co}, \mathrm{Cr}$ e $\mathrm{Al}$; os teores de $\mathrm{Se}, \mathrm{Mn}$ e Mo não são alterados.

2. Apenas $10 \%$ de soja no extrato hidrossolúvel desidratado (100 g) já pode atender $100 \%$ do $\mathrm{Mg}$, $\mathrm{Cu}, \mathrm{Co}, \mathrm{Zn}, \mathrm{Cr}, \mathrm{Se}, \mathrm{Mn}, \mathrm{Mo}$ e Al indicados para lactentes diariamente; $20 \%$ de soja pode suprir $100 \%$ do K recomendado; $40 \%$ de soja pode atender $100 \%$ do $\mathrm{P}$ recomendado.

\section{REFERÊNCIAS}

AMERICAN ASSOCIATION OF CEREAL CHEMISTS (Saint Paul, Estados Unidos). Approved methods of the American Association of Cereal Chemists. 7.ed. St. Paul, 1969. 2v.

ASSOCIATION OF OFFICIAL ANALYTICAL CHEMISTS (Gaithersburg, Estados Unidos). Official methods of analysis. 16.ed. Washington, 1997. v.1, Ch.9, p.1-9.

CRUZ, M.J.S.; COELHO, D.T.; KIBUUKA, G.K.; CHAVES, J.B.P. Caracterização química da farinha mista de arroz e soja pré-cozida por extrusão. Revista Ceres, Viçosa, v.30, n.171, p.357-365, 1983.

ELÍAS, L.G.; JOARQUÍN, R.; BRESSANI, R.; ALBERTAZZI, C. Suplementación del arroz con concentrados protéicos. Archivos Latinoamericanos de Nutrición, Caracas, v.18, n.1, p.27-30, 1968.

ESTADOS UNIDOS. Department of Agriculture. Composition of foods. Washington : Agricultural Research Service, 1963. (Agriculture Handbook, 8).

KAKADE, M.L.; SIMONS, N.R.; LIENER, I.E. An evaluation of natural vs. synthetic substrates for measuring the antitrytic activity of soybean samples. Cereal Chemistry, Saint Paul, v.46, n.5, p.518-528, 1969

KAMER, J.H. van de; GINKEL, L. van. Rapid determination of crude fiber in cereals. Cereal Chemistry, Saint Paul, v.29, n.4, p.239-251, 1952.

KRAUSE, M.V.; MAHAN, L.K. Alimentos, nutrição e dietoterapia. 8.ed. São Paulo : Roca, 1994. p.129-163.

NATIONAL RESEARCH COUNCIL (Washington, Estados Unidos). Recommended dietary allowances. 10.ed. Washington : National Academy Press, 1989. 284p.

PIMENTEL-GOMES, F. Curso de Estatística Experimental. 10.ed. São Paulo : Nobel, 1982. 430p.

SEGURA, E.; MAHECHA, G.; MORENO, B.E.; RODRÍGUES, G.S. Desarrollo de un producto alimenticio a base de arroz, para uso infantil. Archivos Latinoamericanos de Nutrición, Caracas, v.38, n.2, p.278-287, 1988.

STEINKE, F.H.; HOPKINS, D.T. Complementary and supplementary effects of vegetable proteins. Cereal Foods World, Saint Paul, v.28, n.6, p.338-341,1983.

WANG, S.H.; CABRAL, L.C.; FERNANDES, S.M. Bebidas à base de extrato hidrossolúvel de arroz $\mathrm{e}$ soja. Ciência e Tecnologia de Alimentos, Campinas, v.17, n.2, p.73-77, 1997.

WILLIANS, S.R. Fundamentos de nutrição e dietoterapia. 6.ed. Porto Alegre : Artes Médicas, 1997. p.144-173. 